\title{
Fungal annexins: a mini review
}

\author{
Kamand Khalaj ${ }^{2}$, Elahe Aminollahi ${ }^{1}$, Ali Bordbar ${ }^{3}$ and Vahid Khalaj ${ }^{{ }^{*}}$
}

\begin{abstract}
The large family of annexins is composed of more than a thousand members which are typically phospholipid-binding proteins. Annexins act in a number of signalling networks and membrane trafficking events which are fundamental to cell physiology. Annexins exert their functions mainly through their calcium-dependent membrane binding abilities; however, some calcium-independent interactions have been documented in the literature. Although mammalian and plant annexins have been well characterized, little is known about this family in fungi. This mini review summarizes the available data on fungal annexins.
\end{abstract}

Keywords: Annexin C, Aspergillus, Fungal physiology

\section{Background}

Annexins are a large multi-gene family of calcium-phospholipid binding proteins which are distributed all over the eukaryotic phyla. This super family has been divided into five major families; A family in vertebrates, B family in invertebrates, $C$ family in fungi, mycetozoa and chromalveolates, D family in plants and E family in protists (Moss and Morgan 2004; Morgan et al. 2006) have reported the first single domain bacterial annexin in Cytophaga hutchinsonii. However, a recent bioinformatic analysis of bacterial genomes has revealed more members of the annexin family in prokaryotes ( $\mathrm{F}$ family) (Kodavali et al. 2014). Figure 1 shows the latest scheme and occurrence of eukaryotic annexins (Cantacessi et al. 2013).

The basic structure of annexins is composed of both a conserved core domain and a variable $\mathrm{N}$-terminal region. The core is made up of $\sim 70$ amino acid repeats which contain the consensus endonexin sequence GXGT....D/E, and normally participates in the formation of type II $\mathrm{Ca}^{2+}$ binding sites (Geisow et al. 1986). Sequences specifying 'type III' $\mathrm{Ca}^{2+}$ binding sites as well as a phosphatidylserine-binding sequence have been identified (Weng et al. 1993; Montaville et al. 2002). The variable N-terminal region of annexins is supposed to be involved in

\footnotetext{
*Correspondence: khalajs@pasteur.ac.ir

${ }^{1}$ Medical Biotechnology Department, Biotechnology Research Center,

Pasteur Institute of Iran, Tehran, Iran

Full list of author information is available at the end of the article
}

regulatory functions, including protein-protein interactions and membrane localization (Hayes et al. 2004).

Annexins have been identified in a wide range of fungi including ascomycetes, basidiomycetes and oomycetes (which are taxonomically distinct from true fungi) (Moss and Morgan 2004; Khalaj et al. 2004b). Despite a large number of studies on mammalian and plant annexins, little is known about fungal annexins. In this review, we sought to focus on the available data regarding the fungal annexins.

\section{History}

The first fungal annexin was identified in ascomycete Neurospora crassa using a bioinformatic approach (Braun et al. 1998). The identified protein displayed $\sim 35 \%$ identity to its orthologue in slime mold Dictyostelium discoideum. In this line, the authors named this gene as anx14 in accordance with $D$. discoideum. Khalaj et al. (2004a) isolated and characterized an annexin homologue from Aspergillus niger using a degenerative PCR approach. More members of the fungal annexin family were then identified through EST database searches and some of them characterized experimentally (Khalaj et al. 2004b). Although there is no evidence for the presence of these proteins in yeasts Saccharomyces cerevisiae, Candida albicans or Schizosaccharomyces pombe, the annotation of the Yarrowia lipolytica genome has confirmed the presence of an annexin member in this yeast (Khalaj et al. 2004b; Braun et al. 2000; Morgan et al. 2004). In addition, annexins have been found in oomycetes. The

\section{望 Springer}




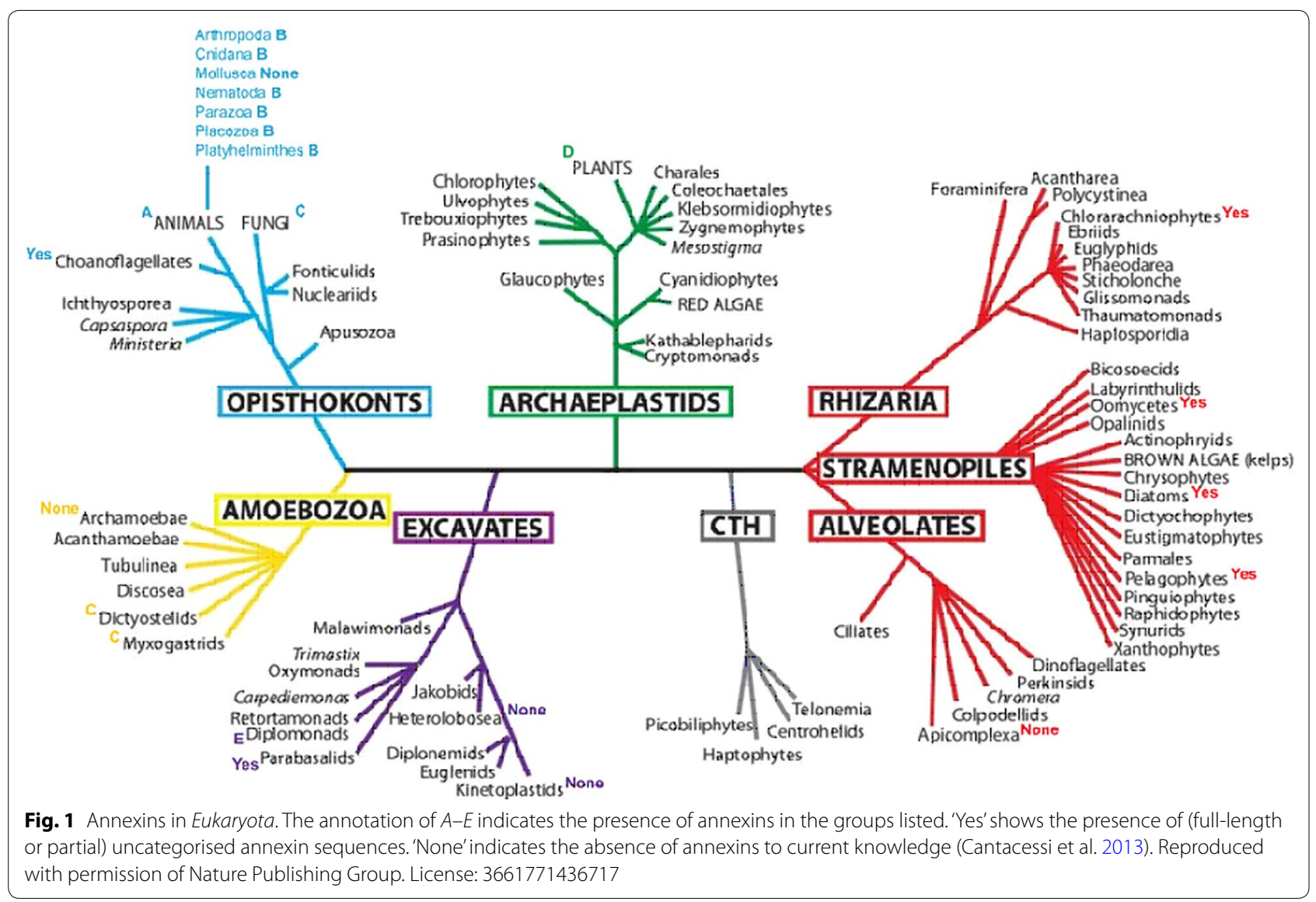

first oomycete annexin was isolated from Saprolegnia monoica using biochemical methods, followed by DNA sequence analysis (Bouzenzana et al. 2006). A recent examination of detergent-resistant membrane microdomains from $S$. monoica has reconfirmed the presence of different isoforms of a $35-\mathrm{kDa}$ annexin in this oomycete (Briolay et al. 2009). Furthermore, the proteome surveys of Phytophthora ramorum and Phytophthora infestans cell walls have identified two annexin homologues in these fungal-like organisms (Meijer et al. 2006; GrenvilleBriggs et al. 2010).

\section{Phylogeny}

The phylogeny analysis of annexins has been demanding due to the different number of orthologues and paralogues found in a certain species. Also the accurate phylogeny analysis of annexins requires an extensive and careful examination of all available sequences, gene and protein structures as well as chromosomal locations (Cantacessi et al. 2013). Despite the availability of genome sequence for a large number of fungal genomes, no comprehensive phylogenic analysis of fungal annexins is available. In general, the fungal annexins are poorly clustered with mammalian annexins and grouped in a single clade (ANXC) containing fungal, mycetozoan and chromalveolates annexins (Gerke and Moss 2002; Moss and Morgan 2004). In the present review, we have performed a small scale phylogeny analysis to demonstrate evolutionary relationship between some fungal annexins (Fig. 2). Based on the presented phylogeny tree, ANXC1 and ANXC2 from $D$. discoideum seem to be most closely related to each other than to any other fungal subfamily. These annexins can be considered as distinct subfamilies, but designated as ANXC1A and ANXC1B because of a lineage-specific gene duplication. In a phylogenetic analysis of fungal annexins by Morgan et al. (2004), the Dictyostelium (which is not a fungus) annexin has also been presented as an out group in the fungal annexin phylogeny tree.

In our previous works, we identified three fungal annexins in Aspergillus fumigatus. Two of these proteins were called as ANXC3.1 and ANXC3.2 with $40 \%$ identity in the protein level, while the third member, ANXC4, was identified as a novel annexin with significant differences, when compared to other fungal and human annexins (Khalaj et al. 2004a, b). These newly identified proteins 


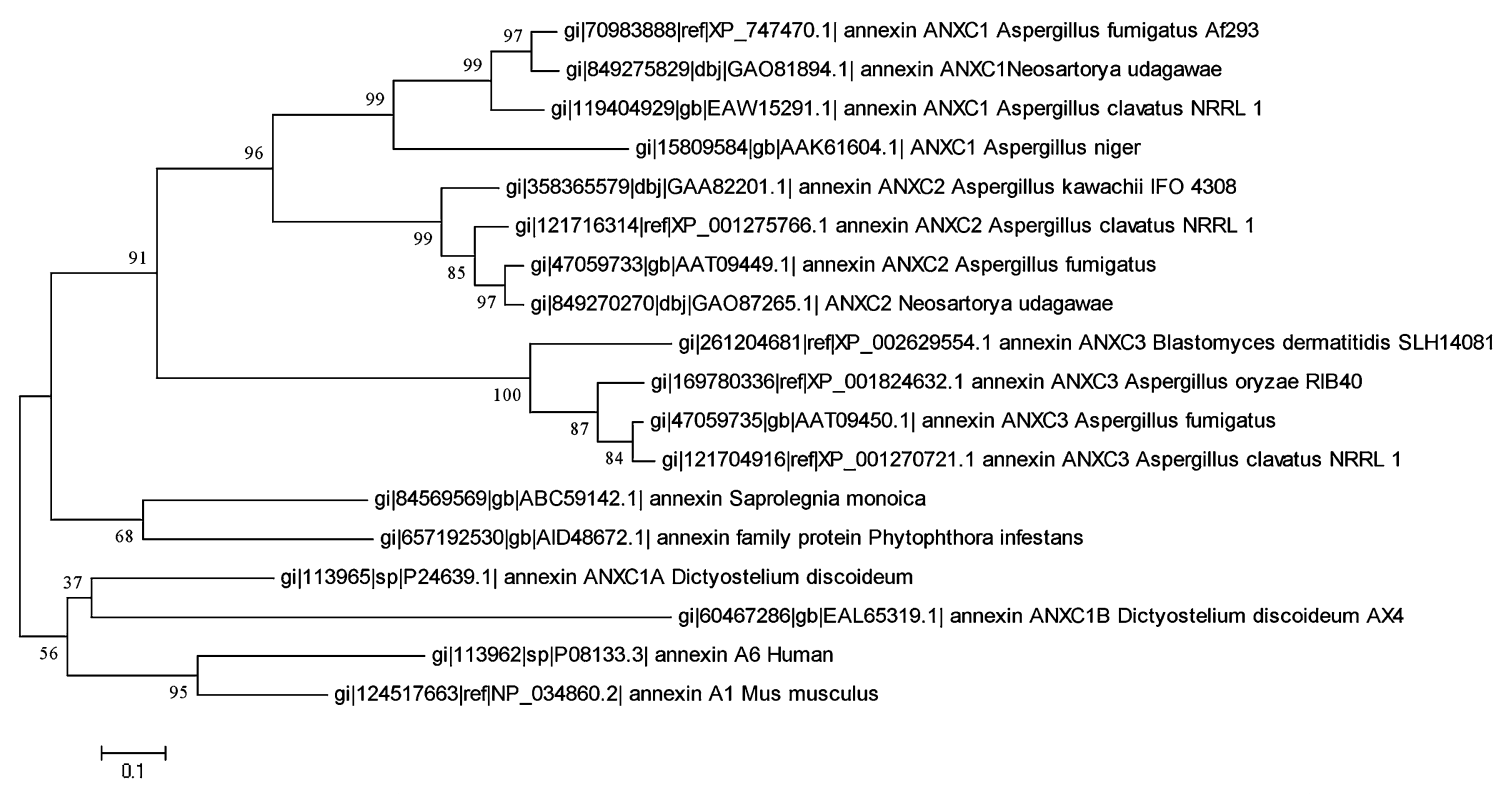

Fig. 2 Molecular Phylogenetic analysis of fungal annexins by Maximum Likelihood method. The evolutionary history was inferred by using the maximum likelihood method based on the JTT matrix-based model. The tree with the highest log likelihood (-7071.5193) is shown. The percentage of trees in which the associated taxa clustered together is shown next to the branches. Initial tree(s) for the heuristic search were obtained automatically as follows. A discrete Gamma distribution was used to model evolutionary rate differences among sites [five categories (+G, parameter $=1.2474)$ ]. The tree is drawn to scale, with branch lengths measured in the number of substitutions per site. The analysis involved 18 amino acid sequences. All ambiguous positions were removed for each sequence pair. There were a total of 430 positions in the final dataset. Human and mouse annexins have been included as an outgroup. Evolutionary analyses were conducted in MEGA5 (Tamura et al. 2011)

were given the name based on next available number in annexin $\mathrm{C}$ group (ANXC1 and ANXC2 previously referred to $D$. disodium). The presented phylogeny tree in this review, generally separates ANC3.1, ANX C3.2 and ANXC4 and we make corrections on the previous classification. In this sense ANXC3.1 renamed as ANXC1; ANC3.2 as ANXC2 and ANXC4 as ANXC3. A phylogenetic analysis of the annexin sequence isolated from oomycete $S$. monoica and available EST from other genus of this class, Phytophthora, have shown a well grouped oomycete clade with a high bootstrap support (Bouzenzana et al. 2006). The same situation can be observed for oomycete annexins in the presented tree.

\section{Expression, localization and function}

In the higher eukaryotes, depending on the annexin type and the expressing tissue, the gene expression can follow either a constitutive or a highly inducible pattern. In the cellular level, annexins are generally localized in cytosol but partly associated with membranes or cytoskeleton components (Solito et al. 1998; Pratt and Horseman 1998).

Of known members of the ANXC family, two Dictyostelium annexins have been studied in detail (Doring et al. 1991; Greenwood and Tsang 1991; Marko et al. 2006). Based on what Marko et al. (2006) have nicely presented, both Dictyostelium annexins are expressed at a low but constant level during the development. In localization studies, the ANXC1A-GFP fusion protein was present along the cell membrane, in the cytosol, the nucleus and the endosomal compartment, while ANXC1B-GFP fusion labelled the plasma membrane and partially colocalized with Golgi apparatus markers.

A detailed analysis of $a n x c 1$ in filamentous fungus, $A$. niger, confirmed the constitutive expression of this gene (Khalaj et al. 2004a). An ANXC1-GFP fusion construct, driven by an inducible promoter, has been made in our lab and successfully expressed in A. niger (unpublished data). Upon the induction of this expression cassette, a cytosolic distribution of the fusion protein has been observed.

In biochemical studies of Saprolegnia cell wall components, an annexin homologue has been co-purified with a cell wall enzyme, $(1 \rightarrow 3)-\beta$-D-glucan synthase. This may demonstrate a membrane localization for this protein (Bouzenzana et al. 2006; Briolay et al. 2009).

The proposed functions of annexins are based mainly on $\mathrm{Ca}^{2+}$ /phospholipid binding properties in co-operation with various partners (Rescher and Gerke 2004). The most known functions of the annexin family include participation in membrane organization and trafficking events such as endocytosis and exocytosis, ion channel 
modulation, as well as some extracellular activities like receptor-ligand interactions (Monastyrskaya et al. 2009a, b; Gerke and Moss 2002; Kourie and Wood 2000). However, a number of $\mathrm{Ca}^{2+}$ independent activities have also been assigned (Mortimer et al. 2008; Gerke and Moss 2002).

The examination of amino acid sequences of ANXC1 and ANXC2 in Aspergillus fumigatus have revealed a well-conserved core region compared to other annexins. The calcium-binding repeat regions I and II were found to be similar to those detected in human annexin VII and ANXC1A in D. discoideum. These repeats also contain the consensus phosphatidylserine binding sites. However, for the fourth repeat, there is a very low amino acid identity particularly in the calcium coordinating residues.

The ANXC3 core region has also been examined, showing a little or no conserved endonexin fold, type II $\mathrm{Ca}^{2+}$ binding site or phosphatidylserine-binding sequences. Based on the above analysis, it has been suggested that ANXC3 may not interact with calcium or membranes in a conventional route (Khalaj et al. 2004a, b).

Loss-of-function experiments using gene deletion or RNAi methodology in mammalians resulted in various phenotypes ranging from normal to embryonic lethal (Brachvogel et al. 2003; Clemen et al. 2003). The results are difficult to interpret, partly due to compensatory function of other annexins as well as difference in genetic background of experimental models (Hannon et al. 2003).

Indeed, the first annexin knock out generated for anxc1 in $D$. discoideum failed to lead to any change in essential cell functions. However, the introduction of low external $\mathrm{Ca}^{2+}$ resulted in defects in growth, motility, and chemotaxis of knock out strain, demonstrating a role for annexin $\mathrm{C} 1$ in $\mathrm{Ca}^{2+}$ homeostasis (Doring et al. 1991, 1995).

There is abundant documentation on the role of calcium in fungal tip growth (Jackson and Heath 1993; Garrill et al. 1993; Heath and Geitmann 2000). A variety of imaging and measuring methods have repeatedly shown that the growing mycelia have a high concentration of calcium at their tips (Kim et al. 2012). Likewise, several reports have demonstrated the role of calcium in polar growth of pollen tubes, root hairs and fern rhizoids. (Steer 1989; Hepler 2005; Clark et al. 2005; Bushart and Roux 2007). These observations along with the localization of annexins at the tip of latter cells can emphasize the role of these calcium binding proteins in growth physiology of plants (Konopka-Postupolska et al. 2011).

To investigate the possible role of fungal annexins in tip growth and protein secretion, an anxc1 knock out strain of $A$. niger has been generated (Khalaj et al. 2004a). Normal growth phenotype and intact secretion capacity of the $\mathrm{KO}$ strain, even in low $\mathrm{Ca}^{2+}$ concentrations, suggest a non-essential function of this gene in growth and protein secretion. Disruption of other member of fungal annexins, anxc3, in human pathogen $A$. fumigatus resulted in no obvious phenotype related to the growth or protein secretion. A comparative protein profiling of $\delta a n x c 3$ mutant revealed the modification of respiratory chain proteins and stress response proteins in this mutant. In this sense, a possible anti-stress function has been proposed for ANXC3 in A. fumigatus (Khalaj et al. 2011). In this line, several studies have highlighted the protective role of annexins against various stresses such as oxidative stress, heavy metal stress and osmotic stress in plants (Jami et al. 2008; Konopka-Postupolska et al. 2009; Laohavisit et al. 2010).

The study of annexin-interacting proteins has been an approach in elucidation of the annexin biological functions. As an example, co-purification of a 34-kD annexin protein with $(1 \rightarrow 3)-\beta$-D-glucan synthase in Saprolegnia suggests its role in modulation of this cell wall synthesis enzyme. Add-back experiments using purified annexin have confirmed a positive regulatory effect on glucan synthase activity which needs an optimal ratio of enzyme/ annexin (Bouzenzana et al. 2006). Similarly, the presence of two cell-wall associated annexins in the plant pathogen $P$. infestans may indicate the importance of these proteins in mycelia growth and penetration of this pathogen into the host tissue (Grenville-Briggs et al. 2010).

Shirakawa et al. (2005) have identified two aminoacyltRNA synthases as annexin binding proteins in true slime mold, Physarum polycephalum. They have suggested that there is a possible relationship between membrane trafficking and protein machinery. More studies are needed to confirm such activities in fungi.

\section{Conclusion}

Several potential functions have been assigned to the fungal annexins. The presence of this family in fungi may suggest a role in providing the particular needs of these organisms. The advantage of low numbers of fungal annexins (e.g., 3 in ascomycetes), together with fewer cell types, provides an excellent opportunity for elucidating the biological functions of these proteins. In this case, a comprehensive multi-gene deletion study along with omics-based investigations can give us a deeper insight into the possible role of annexins in fungal development, the adaptation of fungi to different environments and also, pathogenesis. Furthermore, the identification of annexin binding partners and characterization of their possible functional complexes may be helpful in understanding the relevant biological processes.

\section{Authors' contributions}

KK reviewed the published data and prepared the initial draft. EA collaborated in manuscript preparation. AB collaborated in phylogeny analysis. VK designed the structure of the review, supervised the manuscript preparation and 
revised and finalized the manuscript. All authors read and approved the final manuscript.

\section{Author details \\ ${ }^{1}$ Medical Biotechnology Department, Biotechnology Research Center, Pasteur Institute of Iran, Tehran, Iran. ${ }^{2}$ Medicine Faculty, Tehran University of Medi- cal Sciences, Tehran, Iran. ${ }^{3}$ Molecular Systematics Laboratory, Parasitology Department, Pasteur Institute of Iran, Tehran, Iran. \\ Acknowledgements \\ We would like to express our gratitude to Professor Reginald O Morgan at University of Oviedo for his excellent comments on phylogeny analysis.}

\section{Competing interests}

The authors declare that they have no competing interests.

Received: 3 June 2015 Accepted: 9 November 2015

Published online: 24 November 2015

\section{References}

Bouzenzana J, Pelosi L, Briolay A, Briolay J, Bulone V (2006) Identification of the first Oomycete annexin as a $(1 \rightarrow 3)$-beta-D-glucan synthase activator. Mol Microbiol 62(2):552-565

Brachvogel B, Dikschas J, Moch H, Welzel H, von der Mark K, Hofmann C, Poschl E (2003) Annexin A5 is not essential for skeletal development. Mol Cell Biol 23(8):2907-2913

Braun EL, Kang S, Nelson MA, Natvig DO (1998) Identification of the first fungal annexin: analysis of annexin gene duplications and implications for eukaryotic evolution. J Mol Evol 47(5):531-543

Braun EL, Halpern AL, Nelson MA, Natvig DO (2000) Large-scale comparison of fungal sequence information: mechanisms of innovation in Neurospora crassa and gene loss in Saccharomyces cerevisiae. Genome Res 10(4):416-430

Briolay A, Bouzenzana J, Guichardant M, Deshayes C, Sindt N, Bessueille L, Bulone V (2009) Cell wall polysaccharide synthases are located in detergent-resistant membrane microdomains in oomycetes. Appl Environ Microbiol 75(7):1938-1949

Bushart TJ, Roux SJ (2007) Conserved features of germination and polarized cell growth: a few insights from a pollen-fern spore comparison. Ann Bot 99(1):9-17

Cantacessi C, Seddon JM, Miller TL, Leow CY, Thomas L, Mason L, Willis C, Walker G, Loukas A, Gasser RB, Jones MK, Hofmann A (2013) A genomewide analysis of annexins from parasitic organisms and their vectors. Sci Rep 3:2893

Clark G, Cantero-Garcia A, Butterfield T, Dauwalder M, Roux SJ (2005) Secretion as a key component of gravitropic growth: implications for annexin involvement in differential growth. Gravit Space Biol Bull 18(2):113-114

Clemen CS, Herr C, Hovelmeyer N, Noegel AA (2003) The lack of annexin A7 affects functions of primary astrocytes. Exp Cell Res 291(2):406-414

Doring V, Schleicher M, Noegel AA (1991) Dictyostelium annexin VII (synexin) CDNA sequence and isolation of a gene disruption mutant. J Biol Chem 266(26):17509-17515

Doring V, Veretout F, Albrecht R, Muhlbauer B, Schlatterer C, Schleicher M, Noegel AA (1995) The in vivo role of annexin VII (synexin): characterization of an annexin VII-deficient Dictyostelium mutant indicates an involvement in $\mathrm{Ca}(2+)$-regulated processes. J Cell Sci 108(Pt 5):2065-2076

Garrill A, Jackson SL, Lew RR, Heath IB (1993) Ion channel activity and tip growth: tip-localized stretch-activated channels generate an essential $\mathrm{Ca}^{2+}$ gradient in the oomycete Saprolegnia ferax. Eur J Cell Biol 60(2):358-365

Geisow MJ, Fritsche U, Hexham JM, Dash B, Johnson T (1986) A consensus amino-acid sequence repeat in Torpedo and mammalian $\mathrm{Ca}^{2+}$-dependent membrane-binding proteins. Nature 320(6063):636-638

Gerke V, Moss SE (2002) Annexins: from structure to function. Physiol Rev 82(2):331-371

Greenwood M, Tsang A (1991) Sequence and expression of annexin VII of Dictyostelium discoideum. Biochim Biophys Acta 1088(3):429-432
Grenville-Briggs $\sqcup$, Avrova AO, Hay RJ, Bruce CR, Whisson SC, van West P (2010) Identification of appressorial and mycelial cell wall proteins and a survey of the membrane proteome of Phytophthora infestans. Fungal Biol 114(9):702-723

Hannon R, Croxtall JD, Getting SJ, Roviezzo F, Yona S, Paul-Clark MJ, Gavins FN, Perretti M, Morris JF, Buckingham JC, Flower RJ (2003) Aberrant inflammation and resistance to glucocorticoids in annexin 1-/- mouse. FASEB J 17(2):253-255

Hayes MJ, Rescher U, Gerke V, Moss SE (2004) Annexin-actin interactions. Traffic 5(8):571-576

Heath IB, Geitmann A (2000) Cell biology of plant and fungal tip growth-getting to the point. Plant Cell 12(9):1513-1517

Hepler PK (2005) Calcium: a central regulator of plant growth and development. Plant Cell 17(8):2142-2155

Jackson SL, Heath IB (1993) Roles of calcium ions in hyphal tip growth. Microbiol Rev 57(2):367-382

Jami SK, Clark GB, Turlapati SA, Handley C, Roux SJ, Kirti PB (2008) Ectopic expression of an annexin from Brassica juncea confers tolerance to abiotic and biotic stress treatments in transgenic tobacco. Plant Physiol Biochem 46(12):1019-1030

Khalaj V, Hey P, Smith L, Robson GD, Brookman J (2004a) The Aspergillus niger annexin, anxC3.1 is constitutively expressed and is not essential for protein secretion. FEMS Microbiol Lett 239(1):163-169

Khalaj V, Smith L, Brookman J, Tuckwell D (2004b) Identification of a novel class of annexin genes. FEBS Lett 562(1-3):79-86

Khalaj V, Azarian B, Enayati S, Vaziri B (2011) Annexin C4 in A. fumigatus: a proteomics approach to understand the function. J Proteomics 74(10):1950-1958

Kim HS, Czymmek KJ, Patel A, Modla S, Nohe A, Duncan R, Gilroy S, Kang S (2012) Expression of the Cameleon calcium biosensor in fungi reveals distinct $\mathrm{Ca}(2+)$ signatures associated with polarized growth, development, and pathogenesis. Fungal Genet Biol 49(8):589-601

Kodavali PK, Dudkiewicz M, Pikula S, Pawlowski K (2014) Bioinformatics analysis of bacterial annexins - putative ancestral relatives of eukaryotic annexins. PLoS One 9(1):e85428

Konopka-Postupolska D, Clark G, Goch G, Debski J, Floras K, Cantero A, Fijolek B, Roux S, Hennig J (2009) The role of annexin 1 in drought stress in Arabidopsis. Plant Physiol 150(3):1394-1410

Konopka-Postupolska D, Clark G, Hofmann A (2011) Structure, function and membrane interactions of plant annexins: an update. Plant Sci 181(3):230-241

Kourie Jl, Wood HB (2000) Biophysical and molecular properties of annexinformed channels. Prog Biophys Mol Biol 73(2-4):91-134

Laohavisit A, Brown AT, Cicuta P, Davies JM (2010) Annexins: components of the calcium and reactive oxygen signaling network. Plant Physiol 152(4):1824-1829

Marko M, Prabhu Y, Muller R, Blau-Wasser R, Schleicher M, Noegel AA (2006) The annexins of Dictyostelium. Eur J Cell Biol 85(9-10):1011-1022

Meijer HJ, van de Vondervoort PJ, Yin QY, de Koster CG, Klis FM, Govers F, de Groot PW (2006) Identification of cell wall-associated proteins from Phytophthora ramorum. Mol Plant Microbe Interact 19(12):1348-1358

Monastyrskaya K, Babiychuk EB, Draeger A (2009a) The annexins: spatial and temporal coordination of signaling events during cellular stress. Cell Mol Life Sci 66(16):2623-2642

Monastyrskaya K, Babiychuk EB, Hostettler A, Wood P, Grewal T, Draeger A (2009b) Plasma membrane-associated annexin A6 reduces $\mathrm{Ca}^{2+}$ entry by stabilizing the cortical actin cytoskeleton. J Biol Chem 284(25):17227-17242

Montaville P, Neumann JM, Russo-Marie F, Ochsenbein F, Sanson A (2002) A new consensus sequence for phosphatidylserine recognition by annexins. J Biol Chem 277(27):24684-24693

Morgan RO, Martin-Almedina S, Iglesias JM, Gonzalez-Florez MI, Fernandez MP (2004) Evolutionary perspective on annexin calcium-binding domains. Biochim Biophys Acta 1742(1-3):133-140

Morgan RO, Martin-Almedina S, Garcia M, Jhoncon-Kooyip J, Fernandez MP (2006) Deciphering function and mechanism of calcium-binding proteins from their evolutionary imprints. Biochim Biophys Acta 1763(11):1238-1249

Mortimer JC, Laohavisit A, Macpherson N, Webb A, Brownlee C, Battey NH, Davies JM (2008) Annexins: multifunctional components of growth and adaptation. J Exp Bot 59(3):533-544 
Moss SE, Morgan RO (2004) The annexins. Genome Biol 5(4):219

Pratt SL, Horseman ND (1998) Identification of two Y-box binding proteins that interact with the promoters of columbid annexin I genes. Gene 214(1-2):147-156

Rescher U, Gerke V (2004) Annexins--unique membrane binding proteins with diverse functions. J Cell Sci 117(Pt 13):2631-2639

Shirakawa T, Nakamura A, Kohama K, Hirakata M, Ogihara S (2005) Class-specific binding of two aminoacyl-tRNA synthetases to annexin, a $\mathrm{Ca}^{2+}$ - and phospholipid-binding protein. Cell Struct Funct 29(5-6):159-164

Solito E, de Coupade C, Parente L, Flower RJ, Russo-Marie F (1998) IL-6 stimulates annexin 1 expression and translocation and suggests a new biological role as class II acute phase protein. Cytokine 10(7):514-521
Steer M (1989) Calcium control of pollen tube tip growth. Biol bull 176(2S):18-20

Tamura K, Peterson D, Peterson N, Stecher G, Nei M, Kumar S (2011) MEGA5: molecular evolutionary genetics analysis using maximum likelihood, evolutionary distance, and maximum parsimony methods. Mol Biol Evol 28(10):2731-2739

Weng X, Luecke H, Song IS, Kang DS, Kim SH, Huber R (1993) Crystal structure of human annexin I at 2.5 A resolution. Protein Sci 2(3):448-458

\section{Submit your manuscript to a SpringerOpen ${ }^{\circ}$ journal and benefit from:}

- Convenient online submission

- Rigorous peer review

- Immediate publication on acceptance

- Open access: articles freely available online

- High visibility within the field

- Retaining the copyright to your article

Submit your next manuscript at $>$ springeropen.com 